\title{
RECURSOS PEDAGÓGICOS: "KIT" DE OBJETOS INFANTIS INDÍGENAS
}

\author{
Camilo de Mello Vasconcellos* \\ Carla Gibertoni Carneiro* \\ Judith Mader Elazari*
}

\begin{abstract}
A Divisão de Difusão Cultural do Museu de Arqueologia e Etnologia da Universidade de São Paulo estabeleceu como uma de suas prioridades educacionais, no âmbito de seu Programa de Recursos Educativos e Museográficos, a elaboração de Materiais Pedagógicos. Estes são considerados recursos educacionais fundamentais para os professores utilizarem em sala de aula, visando, entre outros objetivos, a preparação de seus alunos para as visitas às exposições do Museu de Arqueologia e Etnologia da Universidade de São Paulo.

Além dos recursos já existentes tais como o "kit" de Objetos Arqueológicos e Etnográficos e a Valise Pedagógica Origens do Homem, foi elaborado em 2003 o "kit" de Objetos Infantis Indígenas.

Este material pedagógico, concebido pela equipe de educadores do Serviço Técnico de Musealização do MAE/USP, é um recurso que propicia, especialmente ao público escolar, o conhecimento de alguns aspectos da cultura de crianças de diferentes sociedades indígenas.

Propomos por intermédio deste material desafios que envolvem várias habilidades cognitivas: manuseio, observação, questionamento, investigação, comparação, reflexão, além de desenvolver atitudes que permitem a cada um perceber a diversidade cultural dos povos indígenas, a partir da análise e do conhecimento de algumas de suas características, principalmente aquelas relativas à socialização das crianças

A utilização deste tipo de material didático pretende alcançar alguns objetivos, tais como:
\end{abstract}

(*) Museu de Arqueologia e Etnologia da Universidade de São Paulo, Serviço Técnico de Musealização, Área de Educação. cmvasco@usp.br cgiber@usp.br judimel@usp.br
1. Discutir a relação entre diferentes documentos, vestígios, suportes e veículos de informação que possibilitem a compreensão da infância em diferentes grupos indígenas;

2. Subsidiar professores para que preparem seus alunos para uma visita ao MAE/USP, que possui em seu acervo importantes coleções etnográficas brasileiras;

3. Propiciar situações de ensino que envolvam a questão indígena, especialmente relacionada à diversidade cultural entre as sociedades;

4. Demonstrar que os museus podem ser vistos como "laboratórios pedagógicos", sugerindo e oferecendo formas alternativas e específicas de ensino e aprendizagem;

5. Traçar paralelos entre as experiências lúdicas das crianças indígenas e não indígenas;

6. Compreender diferentes formas de socialização de crianças em diferentes sociedades e

7. Contribuir para o aprofundamento da reflexão sobre a diversidade cultural entre as sociedades indígenas, aprendendo a ver diferença como uma riqueza no desenvolvimento do respeito entre as diferentes culturas humanas.

Esse material didático foi elaborado prioritariamente para ser emprestado ao público escolar podendo também atingir outros públicos. Estes deverão participar de uma Orientação prévia, com os educadores do MAE, no sentido de propiciar a exploração didática e o desenvolvimento do potencial educativo deste material. 
O "kit" pedagógico é composto por várias linguagens que podem ser utilizadas separadamente ou relacionadas, a saber:

1. Objetos infantis indígenas ou brinquedos: apito Kayabi, pião Kayabi, boneca Karajá, arco e flecha Nambikuara, ralador Enawene-Nawe e cesto cargueiro Panará;

2. Texto científico: Os brinquedos e a socialização da criança indigena, da etnóloga Nobue Myazaki, com a contextualização dos objetos acima citados e ilustrações;

3. Painéis fotográficos com as seguintes temáticas: Brincadeiras, Contato, Modelagem da boneca Karajá e Crianças;

4. Pranchas com mapas e ilustrações sobre o cotidiano de diferentes grupos indígenas;

5. Vídeo: PEJU KATY KYRIMGUE 'I Venham todas as crianças, um recorte sobre o cotidiano de crianças na aldeia Guarani Krukutu, São Paulo, SP;

6. Sugestões de atividades pedagógicas e

7. Sugestões bibliográficas.

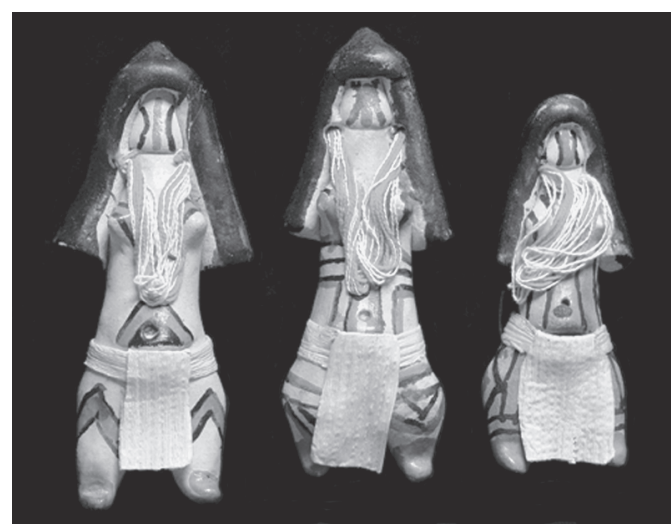

Bonecas Karajá (Foto: Wagner Souza e Silva).

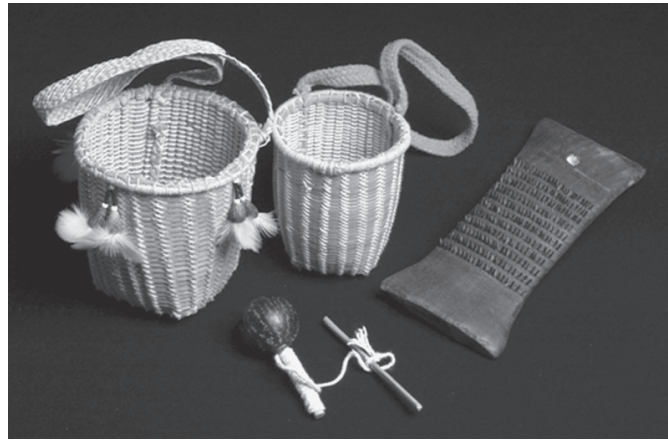

Objetos Infantis Indigenas (Foto: Wagner Souza e Silva).

Propomos também a discussão de alguns temas junto aos alunos antes da utilização do "kit", tais como:

- O papel dos brinquedos/brincadeiras no processo de socialização das crianças indígenas;

- O papel dos brinquedos/brincadeiras na formação dos alunos;

- Adiversidade cultural entre os grupos indígenas;

- A pesquisa etnográfica relacionada ao conhecimento de culturas indígenas;

- A divisão sexual de trabalho nas sociedades indígenas;

- As escolas indígenas no Brasil e

- A exploração do trabalho infantil na nossa sociedade e a participação das crianças indígenas nas atividades produtivas cotidianas.

Sugerimos atividades relacionadas às várias linguagens deste material didático: objetos, painéis, pranchas com ilustrações e vídeo. Essas devem ser adaptadas às distintas faixas etárias dos alunos.

A Orientação para Professores e outros interessados em tomar emprestado este material didático é formada por: apresentação geral; apresentação dos objetivos deste recurso educacional; discussão de conceitos-chave para aprofundamento na utilização do "kit"; exercícios relacionados a cada uma das diferentes linguagens que compõem o material e avaliação. 


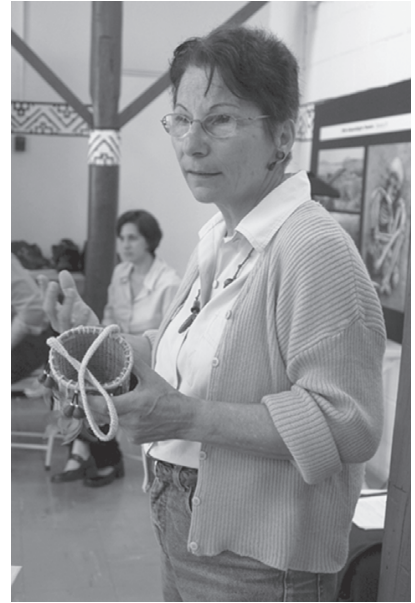

Orientação para professores (Foto: Wagner Souza e Silva).

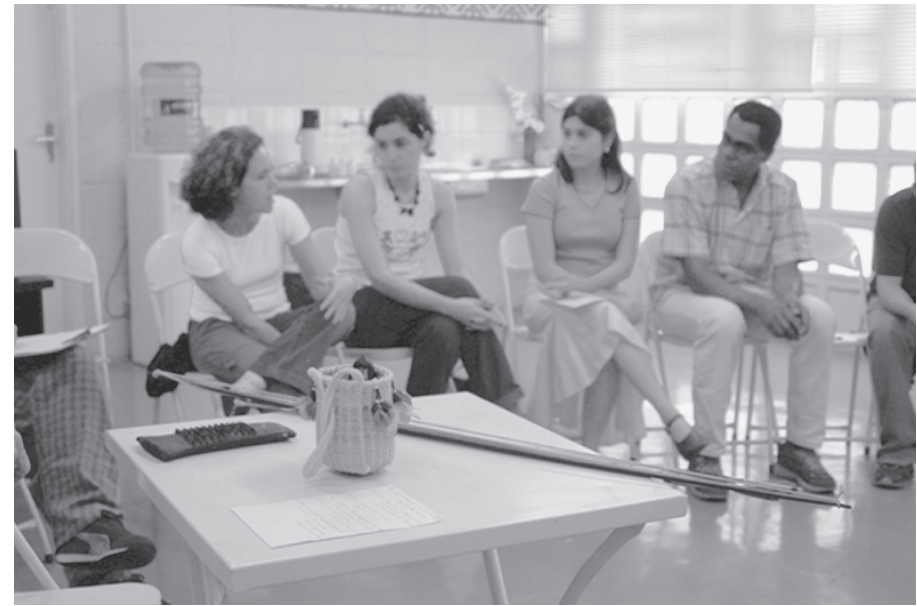

Orientação para Professores (Foto: Wagner Souza e Silva).

Recebido para publicação em 15 de outubro de 2004. 